\title{
Borges, reescritor. En torno a "El escritor argentino y la tradición" y la intriga de sus contextos de publicación
}

\section{Borges, rewriter. Around "El escritor argentino y la tradición" and the intrigue of its publication contexts}

\author{
SEBASTIÁN HERNAIZ \\ Facultad de Filosofía y Letras. Universidad de Buenos Aires. Argentina \\ Correo electrónico: sebsaiz@gmail.com
}

\begin{abstract}
"El escritor argentino y la tradición" de Jorge Luis Borges ha sido leído como un texto central de la estética borgeana por parte de la crítica literaria e incluso como manifiesto estético por distintos grupos de escritores. Sin embargo, poca atención han recibido una serie de elementos textuales que fueron variando en las sucesivas ediciones que tuvo el texto. Proponiendo una lectura de las operaciones que Borges practica en "El escritor y la tradición" a partir de estas variaciones, este trabajo reubica e interpreta el texto en sus contextos editoriales, culturales y políticos.
\end{abstract}

Palabras clave: Jorge Luis Borges, “El escritor argentino y la tradición”, reescritura, peronismo, reediciones.

Jorge Luis Borges' "El escritor argentino y la tradición" has been read as a central text of the author's aesthetics by literary criticism and even as a literary manifesto by different groups of writers. However, little attention has received a series of textual elements that were varied in the successive editions of the text. Proposing a reading of the operations that Borges practices in "El escritor argentino y la tradición" from these variations, this work relocates and interprets the text in its editorial, cultural and political contexts.

Key words: Jorge Luis Borges, “The argentine writer and tradition”, rewriting, peronismo, reissues. 


\section{LA CONFERENCIA}

"El escritor argentino y la tradición" fue originalmente una conferencia que Jorge Luis Borges dictó en el Colegio Libre de Estudios Superiores en $1951 .{ }^{1}$ El texto se publica por primera vez en 1953 en Cursos y conferencias, la revista del Colegio Libre. En 1955 aparece en la revista Sur y finalmente, dos años después, la pieza pasa a formar parte de un libro de Borges: el volumen Discusión, publicado originalmente en 1932 y reeditado por primera vez en 1957. ${ }^{2}$ Desde entonces, figura en las reediciones de ese libro de ensayos de 1932.

En la serie de disputas e interpretaciones en torno al debate sobre la poesía nacional y el color local, "El escritor argentino y la tradición" se ha configurado como un texto fundamental de la literatura argentina del siglo XX y ha sido leído como respuesta a los discursos nacionalistas de la cultura. En su primer contexto de circulación, en 1951, la conferencia participa de esos debates como intervención directa para disputar la legitimidad estética de la política cultural que llevaba a cabo entonces el gobierno peronista, con el que, es sabido, Borges estuvo siempre enfrentado. Pero si bien esta operación de intervención político-estética ha sido señalada últimamente (Louis 2007; Balderston 2013; Piglia 2013), es preciso reconocer que durante mucho tiempo pasó inadvertida y el texto se leyó más bien desacomodado de sus contextos originales de producción y circulación y se lo interpretó descontextualizado ${ }^{3}$ como un manifiesto estético in abstracto, como contrapartida de la faceta más cosmopolita del Borges narrador, como la explicitación estética de las opciones formales que le brindan el importante reconocimiento internacional que obtiene como cuentista desde los años cincuenta y sobre todo desde 1961, cuando recibe el premio Formentor junto a Samuel Beckett. ${ }^{4}$ Así, por ejemplo, es utilizado para explicar el "paso" del "Buenos Aires

\footnotetext{
${ }^{1}$ El Colegio Libre de Estudios Superiores es una institución parauniversitaria fundada en Buenos Aires en los ańos treinta. Durante el peronismo (1945-1955) tuvo como función nuclear profesores e intelectuales liberales que encontraban allí un espacio para dictar cursos y conferencias, al margen de -y en muchos casos de modo confrontativo con- los espacios estatales oficiales (Neiburg 1988).

${ }^{2}$ El mismo año en que se publica en Cursos y conferencias, y sin variantes, se publica también en la revista Panorama. Revista interamericana de Cultura (vol. 2, no 5, Washington: 57-64). En el itinerario que va desde la "versión taquigráfica" -tal como se aclara en Cursos y conferencias- de 1953 hasta la versión de 1957 de Discusión sí se registran algunas variaciones textuales. En algunas de ellas nos detendremos a lo largo de este artículo. En cuanto a las variaciones no éditas de "El escritor argentino y la tradición", ver Balderston (2013).

${ }^{3}$ Si durante años la crítica borgesiana se vio hegemonizada por el modelo de análisis de la "irrealidad", siguiendo el paradigma y léxico practicados por Ana María Barrenechea en su fundacional La expresión de la irrealidad en la obra de Jorge Luis Borges (1957) (originalmente una tesis publicada en 1956 bajo el título The Expression of Unreality in the Work of Borges, correspondiente al Bryn Mawr College), el trabajo de Daniel Balderston, ¿Fuera de contexto? Referencialidad histórica y expresión de la realidad en Borges de 1996 propone una inversión del paradigma, retoma lecturas que no se apoyaban en la idea de "irrealidad" y se proyecta en un amplio espectro de estudios que desde entonces se desarrollan crecientemente.

${ }^{4}$ Para una lectura de cómo se leyó descontextualizado el texto de Borges en la revista Babel, ver "Las tensiones de una revista" (Hernaiz 2011: 7).
} 
criollista" al "Borges Universal" que se podría leer desde Historia universal de la infamia (1935). Pienso, por dar un ejemplo notorio, en el libro de Beatriz Sarlo, Borges, un escritor en las orillas, donde, aún sin cometer el error de dar por fecha del texto el año 1932, Sarlo incluye igualmente los argumentos "universalistas" del Borges de "El escritor argentino y la tradición" como eslabón intermedio que permite narrar el recorrido que se dibuja entre el Evaristo Carriego, de 1930, y los "juegos de un tímido" de 1935 (Sarlo [1995] 2003: 58-63).

Pero en su primer contexto de circulación, en 1951, "El escritor argentino y la tradición" era un texto fuertemente ligado a su coyuntura y se postulaba confrontativo con las políticas culturales del peronismo. Para confrontar con el folklorismo y la exaltación de lo nacional que -según percibían los sectores liberales del momento ${ }^{5}$ era lo que promovía el peronismo como política cultural estatal, Borges estaba entonces incluso dispuesto a pagar el precio de tener que desligarse de la estética y de las ideas promovidas con fruición en sus primeros años como autor: sus ideas estéticas y políticas y sus libros de la década del veinte.

Es precisamente alrededor de las interpretaciones de la obra de Borges de la década del veinte que es preciso traer a colación un texto que opera como importante antecedente e intertexto de "El escritor argentino y la tradición". Nos referimos al inesperado modo del diálogo que en su conferencia propone Borges con el artículo de Héctor Murena "Condenación de una poesía" (1948).

No hace mucho, el crítico y escritor argentino Ricardo Piglia ha caracterizado a ese texto de Murena como un "brulote" (Piglia, 2013: 7'09'") contra la obra de Borges. ${ }^{6}$ Efectivamente, "Condenación de una poesía" aparece en la revista Sur en 1948 y tanto el título como el lugar de publicación del texto ya adelantan el centro de su ataque: condenar una poesía, particularmente la de Borges. En su texto, Murena parte de señalar las diferencias que existen entre lo que él considera el "arte nacional" y el "arte nacionalista", siendo el segundo una mera impostación del primero, con la inevitable consecuencia, desde su perspectiva, de que "La voluntad nacionalista excluye la posibilidad de crear arte nacional” (1948: 77,78). El "arte nacionalista”, en su perspectiva, se caracteriza por prácticas de artistas que "se sitúan ante el país como turistas de buena voluntad, dispuestos a integrar sus poemas con lo que, según un modo de ver extranjero, era más representativo, más pintoresco de la nación" (Murena 1948: 76).

\footnotetext{
${ }^{5}$ Para un análisis de los modos en que los sectores liberales percibieron los procesos político-culturales del primer peronismo ver Avellaneda (1983).

${ }^{6}$ En lo próximo citaremos la lectura de esta polémica que hace Ricardo Piglia refiriéndonos a una fuente singular: en el año 2013 el crítico y escritor participó de un ciclo televisivo en el canal público argentino titulado "Borges por Piglia". El programa consistía básicamente en un ciclo de clases televisadas en las que uno de los más atentos e influyentes lectores de la literatura argentina discutía y releía el legado de la obra de Borges. En todos los casos, las referencias corresponden a la clase emitida el día 28/09/2013, dedicada a analizar las relaciones entre literatura y política en los textos de Borges. Las citas corresponden a un trabajo de transcripción que nos pertenece y está basado en los registros audiovisuales disponibles en el canal de YouTube de la TV Pública Argentina. La reposición online divide al programa en 4 bloques. Las citas utilizadas son del segundo bloque. Citamos aclarando el minuto y segundos del inicio de la referencia.
} 
Publicado el "brulote" tres años antes de la conferencia de Borges, cualquier parecido con el célebre argumento de los camellos y el Corán presente en "El escritor argentino y la tradición" no puede ser mera coincidencia. ${ }^{7}$ Sobre todo si se tiene en cuenta que, acto seguido, agregaba Murena en su texto en 1948:

he acentuado deliberadamente la distinción entre arte nacional y arte nacionalista y he hecho de este último una especie de parodia del primero. He escrito las líneas anteriores pensando en el último movimiento literario de carácter nacionalista que se ha producido en el país, en el movimiento que se denominó Martín Fierro (1948: 73).

Y de este grupo -apunta Murena-, Borges será su elemento ejemplar: "Borges tuvo el destino de confundirse casi con la esencia del grupo Martín Fierro" (1948: 76). Y es en la obra de Borges, entonces, que verificará las hipótesis generales desplegadas hasta la exageración desde el principio de su nota:

el poeta describe los símbolos del sentimiento nacional, pero no experimenta el sentimiento nacional (...) la voluntad nacionalista, con su exigencia de tratar lo "verdaderamente" nacional y su consecuente envío hacia el pasado, el caudillo, lo gauchesco, el compadrito, o hacia las formas de interpretación tradicionalistas del presente, significa reducir y empobrecer las formas de la realidad presente de acuerdo con la pequeñez de los tipos del pasado (...); esto implica obligarnos a modos poéticos populares, "familiares", limitados, con los cuales sólo se puede alcanzar una poesía apenas posible de redimir mediante forzados y monstruosos acoplamientos con la metafísica (Murena 1948: 77,78).

Un elemento fundamental que hay que subrayar es que Murena lanza el "brulote" contra Borges condenando su poesía nacionalista de los años veinte en las páginas de la misma revista en la que Borges participa activamente desde los años treinta y donde éste se encuentra publicando, de modo sistemático, no ya poemas "nacionalistas", sino un tipo muy distinto de "ficciones". Por eso es paradójico el modo en que Borges retoma -sin explicitarlo- el texto de Murena: no para una esperable defensa frente al ataque que le propina el "brulote", sino para incorporar sus argumentos, repitiéndolos como modo de evaluar a la distancia sus primeros libros:

Durante muchos años -recuerda Borges-, en libros ahora felizmente olvidados (Luna de enfrente, Evaristo Carriego y otros muchos), yo traté de redactar la sensación, el sabor de los barrios extremos de Buenos Aires; naturalmente abundé

\footnotetext{
${ }^{7}$ Borges retoma casi textualmente algunos de los giros retóricos de la argumentación injuriosa de Murena: "un falsario, un turista, un nacionalista árabe, lo primero que hubiera hecho es prodigar camellos, caravanas de camellos en cada página” (Borges 1974: 270). Leonora Djament (2007) ha trabajado la figura de Murena como ensayista y analiza este vínculo.
} 
en palabras locales, no prescindí de palabras como cuchilleros, milonga, tapia, y otras, y escribí así aquellos olvidables y olvidados libros; luego, hará un año, escribí uno con título La muerte y la brújula que es una especie de pesadilla (Borges, 1953: 520; las cursivas son de Borges).

Este fragmento es particularmente importante por distintas razones. Por un lado, porque en él puede leerse cómo, en 1951, Borges más que polemizar con el texto de Murena decide incorporarlo como modo de caracterizar sus primeras producciones poéticas. De algún modo, el Borges de 1951 comparte con el Murena de 1948 la voluntad de "condenación" de la poesía del Borges de los años veinte: una voluntad que se puede percibir en simultáneo desde 1943 en el modo en que Borges inicia el proceso de reedición y constante corrección de sus primeras obras poéticas. Eso, por un lado. Y por otro: el fragmento es central porque desde la edición en libro de 1957 aparecerá minuciosamente corregido, convirtiéndose en centro de múltiples operaciones estético-políticas de Borges.

A partir de la corrección y reedición del texto, un juego de fechas inestables (o más bien: desestabilizadas) comenzará a ser una de las características del ensayo: una conferencia de 1951 que se lee en una revista recién en 1953 y se publica finalmente en 1957 en la reedición de un libro de 1932, no sólo sin marca alguna que distinga al nuevo texto de los que originalmente eran parte del libro en 1932 sino incluso con correcciones que disimulan su fecha original, su carácter de agregado en el libro y su itinerario previo de apariciones. Veremos algunos efectos de esa inestabilidad de fechado.

\section{LAS FECHAS}

En la clase abierta que dio en la Televisión Pública en septiembre de 2013, Ricardo Piglia dedica un importante espacio de tiempo a analizar "El escritor argentino y la tradición", particularmente a partir de lo que el crítico llama "una intriga" (2013: 6'32") que habría en el texto. Como parte de su exposición, Piglia lee la versión más habitual del fragmento antes referido, es decir, la versión corregida que circula en las ediciones de Emecé desde 1957. Recordemos esta versión para poder acompañar el razonamiento de Piglia y poder comparar el fragmento con su notable aunque levemente distinta versión original:

Séame permitida aquí una confidencia, una mínima confidencia. Durante muchos años, en libros ahora felizmente olvidados, traté de redactar el sabor, la esencia de los barrios extremos de Buenos Aires; naturalmente abundé en palabras locales, no prescindí de palabras como cuchilleros, milongas, tapia, y otras, y escribí así aquellos olvidables y olvidados libros; luego, hará un año, escribí una historia que se llama "La muerte y la brújula" que es una suerte de pesadilla, una pesadilla en que figuran elementos de Buenos Aires deformados por el horror de la pesadilla (Borges 1974: 270; citado en Piglia 2013: 8'18'”). 
La intriga que señala Piglia será central para su interpretación de la conferencia de Borges. Si el cuento "La muerte y la brújula" es sabido que es de 1942, entonces -piensa Piglia- al decir "hará un año", el contexto de enunciación de "El escritor argentino y la tradición" no puede sino moverse hipotéticamente al año 1943. Sin embargo, el hecho es que la conferencia es de 1951 y que su versión impresa es de 1953. ¿Por qué, entonces, Borges, en 1951 (o incluso en 1953), diría que "hará un año" escribió "La muerte y la brújula" si ese cuento es de 1942? Piglia intenta resolver la intriga proponiendo una teoría:

Es un "lapsus deliberado". Yo lo llamo "un lapsus deliberado". Porque el ensayo él lo publica en 1953 en la revista Cursos y conferencias, la revista del Colegio Libre y ahí aparece "hará un año". Luego lo vuelve a publicar en Sur, en el año 55, y vuelve a poner "hará un año". Y luego incluye el texto en la reedición de 1957 del libro Discusión y vuelve a poner "hará un año". O sea que es algo deliberado (Piglia 2013: 9'20').

Es pertinente la metodología de Piglia: conocedor de que Borges reescribe y reubica sus textos de modo sistemático (Louis 1997 y 1999), luego de leer las versiones de más fácil acceso (las Obras completas que Emecé edita desde los años cincuenta o en sus posteriores reediciones), busca las primeras versiones del texto, esas que circulan poco: las primeras ediciones, las publicaciones en revistas. Busca las variantes, no las encuentra y elabora una teoría para lo que ve como constante: "un lapsus deliberado". Este "lapsus" le permite elaborar una teoría que él mismo alcanza a percibir como endeble ("un espiritismo", la llama: "parece una especie de espiritismo"), pero que igualmente intenta sostener:

Borges era muy astuto. Nunca iba a decir "yo acá estoy enunciando en dos lugares a la vez". Nunca lo iba a decir eso: iba a esperar que alguien -que no era yo, porque seguramente, ya digo, alguien lo debe haber visto alguna vez, lo que pasa que yo estoy hablando con ustedes de Borges entonces traigo esta cuestión-... Por lo tanto, la conferencia debe ser leída como una conferencia enunciada en 1943. Parece una especie de espiritismo de la literatura, pero no es un espiritismo de la literatura. Él mismo está pensando en 1943 como el lugar del debate (Piglia 2013: 9'53'”).

Como el cuento "La muerte y la brújula" es de 1942 y como en la cita que Piglia lee Borges decía "hará un año escribí una historia", Piglia concluye: el contexto de enunciación al que Borges se refiere es 1943, corrimiento temporal que volvería de algún modo verdadera la premisa "hará un año que escribí 'La muerte y la brújula”. Y 1943, dirá Piglia, no es cualquier año: es el año del "Poema conjetural", por un lado, pero es, sobre todo, un momento de fuerte expansión del nazismo en Europa (Piglia 2013: 10'58'). Por eso, a continuación, Piglia cita y analiza con lucidez las declaraciones que Borges había hecho sobre el nazismo en 1944. Retoma Piglia: 
dice (Borges) "me he dado cuenta que mi culto al coraje, a los héroes militares, a la tierra, a la sangre y al linaje" -que son la base de su nacionalismo- era lo mismo que lo que estaban haciendo los nazis. Y fíjense lo que dice: "quiero añadir unas palabras sobre un problema que el nazismo propone al escritor. Mentalmente, el nazismo no es otra cosa que la exacerbación de un prejuicio del que adolecen todos los hombres. La certidumbre de la superioridad de su patria, de su idioma, de su religión, de su sangre. Dilatado por la retórica -escribe muy bien Borges, de paso sea dicho-, agravado por el fervor o disimulado por la ironía, esa convicción candorosa es uno de los temas tradicionales de la literatura. No hay sin embargo que olvidar que una secta perversa ha contaminado esas antiguas e inocentes ternuras y que frecuentarlas ahora es consentir o proponer una complicidad. Carezco de toda vocación de heroísmo, de toda facultad política, pero desde 1939 he procurado no escribir una línea que permita esa confusión. Mi vida de hombre es una imperdonable serie de mezquindades. Yo quiero que mi vida de escritor sea un poco más digna”. Entonces dice: si yo sigo en esa línea del nacionalismo, estoy haciendo lo que los nazis están llevando adelante. Era 1943: un año terrible, Hitler estaba dominando toda Europa. Entonces, el efecto, es escribir "La muerte y la brújula", que es un texto sobre el antisemitismo y la tradición judía (Piglia 2013: 11'10").

De este contexto de enunciación será que Piglia derive una encantadora lectura de las tradiciones que atraviesan el cuento "La muerte y la brújula" como abandono del nacionalismo literario que Borges había practicado en esos "libros felizmente olvidados" (su obra de la década del veinte) y como puesta en ficción de los argumentos que casi una década después iría a esbozar en "El escritor argentino y la tradición". Así, resituando en 1943 el momento de enunciación de la conferencia - propone Piglia que estaría pensando Borges- el abandono del color local sería una respuesta al nazismo y la conferencia de 1951, la mera explicitación del por qué de ese abandono.

Aunque seductora, la lectura de Piglia es equivocada. Frente a esta "intriga", proponemos otra respuesta.

\section{UN AŃO}

La hipótesis de lectura política de la obra de Borges que hace Piglia se concentra en el movimiento del contexto de enunciación de 1951 a 1943 a partir del "lapsus deliberado" implicado en la frase "hará un año" que lee en la conferencia de Borges. Sin embargo, esa frase no es tal. Aunque Piglia menciona las publicaciones previas en revistas (Cursos y conferencias en 1953, Sur en 1955), lee siempre el fragmento según la edición corregida que hace circular Borges en la editorial Emecé en el plan de reedición de sus obras completas desde 1957. Es cierto que en las versiones anteriores del texto Borges decía "hará un año", pero decía también otra cosa sobre lo que un año antes había hecho. Volvamos a leer el fragmento de 1953: 
Durante muchos años, en libros ahora felizmente olvidados (Luna de enfrente, Evaristo Carriego y otros muchos), yo traté de redactar la sensación, el sabor de los barrios extremos de Buenos Aires; naturalmente abundé en palabras locales, no prescindí de palabras como cuchilleros, milonga, tapia, y otras, y escribí así aquellos olvidables y olvidados libros; luego, hará un año, escribí uno con título La muerte y la brújula que es una especie de pesadilla (Borges 1953: 520; las cursivas son de Borges, los subrayados son nuestros)

La diferencia es sutil, pero contundente. En la versión de 1957, al corregir el texto para incorporarlo a la reedición de Discusión, sí escribirá "hará un año, escribí una historia" (Borges 1957: 157). Pero en la primera versión registrada (la de 1953 que es recordemos- la reproducción taquigráfica de la conferencia de 1951) se lee "hará un año, escribí uno". Donde "uno" remite a "un libro". Lo que leemos, entonces, no es "lapsus" sino un simple dato que se corresponde con hechos fácilmente verificables: casi un año antes de la conferencia, Borges había publicado, efectivamente, un libro "con título La muerte y la brújula" (Emecé, 1951), donde seleccionaba cuentos provenientes de Historia universal de la infamia, Ficciones y El Aleph.

Recapitulando, entonces: "El escritor argentino y la tradición" no pide ser leído como un texto de 1943, sino que -como es de esperar en general y sin necesidad de recurrir a espiritismos- encuentra su contexto de enunciación y recepción en el tiempo presente en que fue pronunciada la conferencia. Una conferencia, entonces, pronunciada en 1951, muy cerca temporalmente de las elecciones presidenciales de ese ańo y en el marco de una institución como el Colegio Libre de Estudios Superiores, que funcionaba en ese momento como un espacio de referencia y pertenencia para el debate intelectual de los sectores opuestos al peronismo, el movimiento político que dirigía entonces los resortes estatales de la Argentina y que sería cómodamente refrendado por el voto popular en esas elecciones. Otra institución que funcionaba como polo opositor al oficialismo era la Sociedad Argentina de Escritores (SADE), la organización gremial que en esos mismos años Borges presidía. Es importante reubicar, entonces, el texto de Borges en relación con su contexto político, cultural e institucional ya que esto nos habilita otras lecturas y con ellas, otro modo de entender las operaciones que pone en funcionamiento Borges en su vínculo con sus "olvidados" primeros textos.

\section{Los VEINTE}

Dijimos que Murena escribe contra la obra de Borges de los ańos veinte, contra esa poesía de "impostación nacionalista", plena del color local que la mirada turística exigiría. Y, dijimos, llamativamente Borges convoca en su texto la posición de Murena pero no para polemizar con ella y defenderse sino que, por el contrario, retoma sus argumentos y los utiliza para desligarse también él mismo de su primera obra. La pregunta que se 
impone, entonces, es por qué, cuando Murena lo ataca, Borges acata. Tal vez contextualizar la discusión sea nuevamente la mejor forma de proponer algunas respuestas.

Si la estocada de Murena había llegado desde lo más hondo de sus propias filas en la revista Sur, un elemento importante para tener en cuenta es que la de Murena no fue una crítica solitaria. Ese mismo 1948, desde el polo opuesto del espectro político, Borges recibía -paralela y paradójica, opuesta pero similar- otra estocada que se hundía en las características de su obra temprana: en octubre de 1948, la editorial Sudamericana publicó la novela Adán Buenosayres, de Leopoldo Marechal, uno de los más destacados intelectuales y agentes culturales del peronismo. Allí, como parte de la relectura del movimiento martinfierrista ("A mis camaradas martinfierristas", se leía en la dedicatoria de esa primera edición), Marechal construye al personaje de Pereda como nombre en clave para representar a Borges, alrededor del cual, en fuerte sintonía crítica con los argumentos que leíamos en Murena, se parodiará hiperbólicamente la poética criollista practicada por Borges en sus ensayos y poemas de los años veinte ${ }^{8}$.

Y si tanto la crítica de Murena como la novela de Marechal ponían en ridículo o criticaban los alcances poéticos del proyecto literario criollista del Borges de los veinte, más sugestivo aún es que al año siguiente, en 1949, en las páginas de una revista ligada fuertemente al oficialismo peronista como fue la revista Continente ${ }^{9}$, se pueda leer un festejo por el cuarto de siglo de la salida de la revista Martín Fierro. La presentación, bajo el título "Se inició una revolución", es sintomática del estado del debate. Leemos en las páginas de la revista Continente:

Martín Fierro, el acusado, en su hora de mayor intensidad, de extranjerizado, y señalado hoy, por algún representante de la generación más nueva, como vocero de un nacionalismo, empezó como un órgano de arte y crítica libre. Más que para innovar, venía para restaurar (1949: 157).

Es decir: una revista filoperonista, defensora, en términos generales, del nacionalismo como estética y como configuración ideológica, retoma en sus páginas la argumentación que Murena ("algún representante de la generación más nueva") había planteado en Sur, pero invierte el signo de la valoración e incluye a la revista Martín Fierro, nodo central de la vanguardia de los años veinte, en las filas del nacionalismo.

Es interesante, por lo demás, que estos no son gestos aislados. La operación se repite en distintos órganos del nacionalismo cultural. Por ejemplo, en la revista Poesía

\footnotetext{
${ }^{8}$ Estética que, por otro lado, el mismo Marechal había festejado en su momento: en 1925, cuando Borges publica Luna de enfrente, en la revista Martín Fierro Marechal celebraba la aparición del que llama "libro de su entusiasmo". Dice allí el luego autor del Adán Buenosayres: "quiero decir su elogio (...) por el magnífico regalo de belleza que nos hace". Y no sólo rescatará la "belleza" del libro, sino que rescata particularmente "el aspecto más interesante y promisor en Borges: un criollismo nuevo y personal” (Marechal 1925: 4).

${ }^{9}$ Sobre la revista Continente, ver Vázquez (2010).
} 
argentina (1949-1950) puede leerse la inclusión del Borges de los veinte en la tradición nacionalista (Cousido y Hernaiz 2015). Los casos son muchos para enumerarlos aquí. Valga como otro ejemplo una intervención pública del entonces funcionario del gobierno peronista, Leopoldo Marechal, en junio de 1949. Paradójicamente, la intervención de Marechal invierte la valoración estética que el autor pareciera practicar en su novela Adán Buenosayres, pero resulta solidaria en los elementos destacados en las revistas defensoras del nacionalismo cultural. La intervención de Marechal se da cuando participa en el primer ciclo anual de conferencias organizado por la Subsecretaría de Cultura de la Nación, donde el intelectual orgánico del peronismo dedica el cierre de su conferencia titulada "Lo autóctono y lo foráneo en su contenido esencial" a la generación que "se agrupó bajo el nombre de nuestro poema nacional, el Martín Fierro". De esta generación festejará Marechal que: "Las formas y los colores de nuestra tierra están presentes como una obsesión en la sutil poesía de Ricardo Molinari. Ricardo Güiraldes, familiar de las tertulias literarias francesas, escribe Don Segundo Sombra. Francisco Luis Bernárdez, que había llevado sus experiencias hasta el superrealismo, vuelve a las claras y eternas musas tradicionales, y hasta dedica sus versos a los grandes temas civiles. "La Bandera", o "El Libertador". Jorge Luis Borges, en su Fervor de Buenos Aires, toma y enriquece la simplísima cuerda de Evaristo Carriego, o ahonda los temas porteños hasta el rigor metafísico" (Marechal 1950: 181-192).

No es de extrańar, entonces, que Borges procurara "desligarse" -la palabra es suya ${ }^{10}$ - de su obra temprana, es decir, de los textos que publicó en la década del veinte en la búsqueda de construir un "criollismo conversador del mundo": Fervor de Buenos Aires (1923), Inquisiciones (1925), Luna de enfrente (1925), El tamaño de mi esperanza (1926), El idioma de los argentinos (1928), Cuaderno de San Martín (1929) y Evaristo Carriego (1930). Pero esto no sucede directa ni únicamente por las vinculaciones, como sugería Piglia, que se pudieran entablar entre esa temprana obra y el nazismo (estamos en 1951, no en 1943), sino por el modo en que el nacionalismo cultural, hegemónico en el peronismo -ese movimiento que se convertirá en dador de sentidos elemental en el mundo borgeano a partir de 1945-, comienza a leer la obra del primer Borges como su tradición: Borges reniega de su primera obra mientras que el peronismo se apropia de esa obra temprana de Borges y la pone a funcionar como antecedente en el plano estético de los cambios políticoculturales impulsados entre 1945 y 1955.

Contra lo que el sentido común ha instalado sobre Borges (¿o habría que decir: contra lo que Borges ha instalado como sentido común?), ${ }^{11}$ lejos estuvo el autor de considerar

\footnotetext{
${ }^{10}$ En su Borges (2006), en la entrada correspondiente al 23 de enero de 1974, Bioy Casares anota este diálogo con Borges: "Borges me dice, por teléfono, que está corrigiendo las pruebas de sus Obras completas: ‘Estoy absorto ante las inepcias que he escrito. Libros como Evaristo Carriego y Discusión no pueden corregirse. Voy a publicarlos tal cual están, con una notita desligándome" (2006: 1476).

${ }^{11}$ La construcción de la figura de autor de Borges en relación a la intervención política es habitualmente paradójica pero constante y no siempre correlativa a sus prácticas biográficas. "Sólo quiero aclarar que no soy, ni he sido jamás, lo que antes se llamaba un fabulista o un predicador de parábolas y ahora un escritor comprometido (...) no he disimulado nunca mis opiniones, ni siquiera en los años arduos, pero no he permitido
} 
siempre desvinculada la literatura de la política. Así, su criollismo poético fue seña del "tamaño de su esperanza" en los años veinte cuando aunaba su lectura de las figuras políticas e intelectuales del país (Sarmiento, Rosas, Yrigoyen) con su proyecto estético de crear mitos para la ciudad de Buenos Aires. Mientras que a Sarmiento, Borges lo cataloga en 1926 como un "norteamericanizado indio bravo, gran odiador y desentendedor de lo criollo", como contrapartida, Borges postulaba los nombres de Rosas e Yrigoyen ("El tamańo de mi esperanza"); y en la fisura imaginaria que abren esos hombres de "leyenda" buscaba incrustar su proyecto poético criollista, ese que un cuarto de siglo después tildarán de nacionalista y pleno de color local -para criticarlo o para defenderlo- Murena, Marechal y el propio autor, entre otros.

Borges abandonará la perspectiva que milita en diversos textos en los años veinte, pero ese abandono no implica un abandono del carácter político de sus intervenciones: aún cuando éstas puedan parecer tomas de posición estéticas desligadas de una disputa política, en Borges siempre se las rearticula como formas de la intervención política e ideológica. Bien subrayaba Piglia lo que señalaba Borges mismo en 1944 en su exposición en la SADE al plantear el "problema": las decisiones estéticas son decisiones políticas, y los contextos históricos son los que le otorgan el carácter político a las decisiones estéticas (Borges 1945). Sostenida desde sus comienzos como autor, es una lección en la que insistirá toda su vida. Así, las operaciones de distanciamiento y auto-recriminación que haga Borges respecto a sus posturas estético-ideológicas de los años veinte se corresponderán no sólo con el material del pasado sino sobre todo con las posturas estético-ideológicas que el autor vaya asumiendo en cada nuevo contexto. En Borges, las revisiones del pasado serán formas de intervenir tanto estética como políticamente en cada uno de esos nuevos contextos.

Un año antes de su muerte, en 1985, publica en el diario El País, de España, el artículo "Releyendo a Sarmiento". Escribe allí: "El decurso del tiempo modifica los textos; Recuerdos de provincia, releído y revisado ahora, no es ciertamente el libro que yo recorrí hace ya más de 60 años" (Borges 1985). La frase no es original. Cuarenta años antes, prologando el libro del sanjuanino, escribía también: "El decurso del tiempo cambia los libros; Recuerdos de provincia, releído y revisado en los términos de 1943, no es ciertamente el libro que yo recorrí hace veinte años" (Borges 1944: 10). ${ }^{12}$ Aunque Borges cambie radicalmente su posición frente a Sarmiento en lo que va de los ańos veinte a los cuarenta, siempre conservará una concepción contextualista y materialista de la literatura: el contexto histórico modifica los textos. La exposición más cabal y lúcida de esta teoría (política) de la

que interfieran en mi obra literaria" (1974: 1021) declara Borges en su célebre prólogo a El informe de Brodie (1970). En el prólogo a su libro de poemas La moneda de hierro, fechado cuatro meses después del golpe militar de 1976, escribe: "Me sé del todo indigno de opinar en materia política, pero tal vez me sea perdonado añadir que descreo de la democracia, ese curioso abuso de la estadística" (1976: 10).

${ }^{12}$ El prólogo de 1943 se encuentra compilado en Prólogos con un prólogo de prólogos. En esa edición se agrega una posdata: "Posdata de 1974. Sarmiento sigue formulando la alternativa: civilización o barbarie. Ya se sabe la elección de los argentinos. Si en lugar de canonizar el Martín Fierro, hubiéramos canonizado el Facundo, otra sería nuestra historia y mejor" (2011: 184). 
literatura es su relato "Pierre Menard, autor del Quijote", donde el cotejo de los fragmentos de Menard y de Cervantes enseńa con precavida ironía las potencias y las limitaciones que debe tener una lectura para dar sentidos a un texto en relación a sus contextos históricos de recepción y producción.

En 1951, el mismo año que dicta la conferencia "El escritor argentino y la tradición", Borges publica en la revista Sur su "Nota sobre (hacia) Bernard Shaw". Leemos allí también su insistente confianza en la potencia dadora de sentidos de la lectura históricamente situada:

La literatura no es agotable, por la suficiente y simple razón de que un solo libro no lo es. El libro no es un ente incomunicado: es una relación, es un eje de innumerables relaciones. Una literatura difiere de otra, ulterior o anterior, menos por el texto que por la manera de ser leída: si me fuera otorgado leer cualquier página actual -ésta, por ejemplo- como la leerán en el año dos mil, yo sabría cómo será la literatura del año dos mil $(1951: 1,2)$.

Si esta teoría de la literatura y de la lectura propia de Borges la pensamos a la luz de los planteos presentados más arriba sobre "El escritor argentino y la tradición", se derivan algunas consecuencias interesantes de apuntar. Por un lado, si es posible leer, en 1942, en el contexto de "el problema que el nazismo le propone al escritor", al cuento "La muerte y la brújula" como un abandono de los intentos de representar a Buenos Aires mediante el color local y abundando en malevos y compadres, es necesario retomar la pregunta esbozada al principio: ¿por qué en la conferencia de 1951, se señala que "hará un año...” publicó un "libro" cuando a lo que se va a referir es al cuento, a "la historia" de "La muerte y la brújula", que no había escrito un año atrás sino casi una década atrás?

Por un lado, se impone un criterio práctico: es más efectivo señalar algo reciente (1951) que algo pasado hace nueve años (1942). Sin embargo, el argumento se evidencia insuficiente y obliga a señalar uno de los efectos del corrimiento de fechas: lo que se hace al hablar del "libro" y no de "la historia" es fundamentalmente correr, mover la fecha de las operaciones estético-políticas que practica Borges. Pero no mover de 1951 a 1943, como proponía Piglia, sino a la inversa: la fecha que pesa es 1951, momento en que Juan Domingo Perón ocupa la Primera Magistratura de la República Argentina y obtiene su reelección. Con esa intervención cronológica, el autor reubica su operación de mutación estética ${ }^{13} \mathrm{y}$ actualiza su intervención política: si en 1942 el cuento "La muerte y la brújula" podía leerse como una sutil intervención que forma parte de la amplia campaña contra el nazismo ${ }^{14}$ que desarrolla Borges, en 1951 su autor consigue, modificando la fecha con la que hacer referencia al texto, haciendo referencia al "libro" en vez de "a la historia", que "La muerte y

\footnotetext{
${ }^{13}$ Puede encontrarse un desarrollo contemporáneo (y estetizado) en torno al concepto de mutación en el texto "Mutaciones" que Borges publica en la revista Sur (1954) y luego recoge en El hacedor (1960) y sin cambios en sus Obras completas (1974: 798).
}

${ }^{14}$ Sobre la relación de Borges y el nazismo, ver Louis (2007). 
la brújula" sea ya no -o ya no solamente- una intervención contra el nazismo, sino ahora también -y por sobre todo- una operación contra el peronismo. $\mathrm{Si}$, como ha señalado Jorge Panesi (2007), las estrategias críticas que Borges desarrolla durante el nazismo las aplica de modo directo en su concepción del peronismo, no es de extrañar, por ende, que para generar una intervención crítica en 1951 decida actualizar la operación estética realizada casi diez años antes.

\section{INTERVENCIONES}

Consciente como era Borges del carácter político de las intervenciones estéticas, un elemento importante queda pendiente de ser comentado: ¿por qué y siguiendo qué modalidades corrige Borges lo que era en 1951 un dato verdadero ("hará un año escribí un libro") para pasar a uno falso ("hará un año escribí una historia”) en 1957?

Volvemos, así, de nuevo a "la intriga" cronológica con la que comenzamos. En 1957 Borges incluye, con variaciones, en el libro Discusión (cuya primera edición, dijimos, es de 1932) el texto de la conferencia dictada en 1951. La edición de 1957 forma parte del plan de reedición de la obra completa de Borges, pactado con Emecé en 1953 y en el cual ya han sido reeditados para entonces sus otros libros de los años treinta: Evaristo Carriego, Historia universal de la infamia e Historia de la eternidad. Un dato digno de ser tenido en cuenta es que algunos meses después del dictado de su conferencia, en julio de 1952, Borges publica Otras inquisiciones, un nuevo libro en el que recopila ensayos publicados, según se describe desde su portada, en el período "1937-1952". Sin embargo, Borges no incluye su conferencia de 1951 en ese libro de julio de 1952. Podría ser precisamente esa la razón, tal vez: no hay suficiente tiempo entre fines de 1951 y mediados de 1952, como para que la conferencia sea incluida en el volumen editado. Sin embargo, sí se incluyen en la edición de 1952 de Otras inquisiciones textos posteriores como "El pudor de la historia", firmado "Buenos Aires, 1952" y publicado por primera vez recién en marzo de 1952 en el diario La Nación.

Como sea, mucho más iluminador es evitar la historia contrafáctica y cotejar con los materiales que sí tenemos. Así, se puede ver el modo en que Borges sí incluye otra conferencia también dictada en el Colegio Libre de Estudios Superiores en su libro Otras inquisiciones. Hablamos de la conferencia dedicada a Nathaniel Hawthorne, donde leemos (y la referencia se mantiene en la edición de las Obras completas de 1974 y subsiguientes) en una nota al pie indicada desde el título del artículo en su edición en libro: "Este texto es el de una conferencia dictada en el Colegio Libre de Estudios Superiores, en marzo de 1949" (1952: 59; 1974: 670). Mientras que en "El escritor argentino y la tradición", tal como se lee en la reedición de Discusión (1957) y en las reediciones posteriores, encontramos también una nota al pie aclaratoria, pero que sólo dice: "Versión taquigráfica de una clase dictada en el Colegio Libre de Estudios Superiores" (1957: 151; 1974: 267).

Para evitar las hipótesis contrafácticas, cotejar con otro libro cercano en su fecha de reedición ilumina también una estrategia solidaria: como primer volumen de la colección 
Obras completas de Emecé, en 1953 se publica la primera reedición de otro libro de los ańos treinta, Historia de la eternidad (1936). El libro, como casi toda reedición en la obra de Borges, tiene agregados, omisiones y variaciones. Siguiendo una práctica habitual en su política de reediciones, en el prólogo que Borges escribe especialmente para esa reedición, se distinguen los textos agregados: "Dos artículos he agregado que complementan o rectifican el texto: La metáfora de 1952, El tiempo circular de 1943" (1974: 351). La reedición de Discusión, contrariamente a la práctica extendida en las reediciones que lleva adelante en esos años, no incluye un nuevo "Prólogo" escrito especialmente para la reedición, cosa que sí sucede con sendos nuevos prólogos que se agregan a Historia universal de la infamia (1954) y a Evaristo Carriego (1955). El mismo prólogo fechado en 1932 que abría la edición original es el que funciona de umbral (Genette 2001) a la nueva edición de Discusión, con el sólo agregado de una nota al pie. Esta breve nota al pie, de cualquier modo, es por demás significativa, ya que señala que un artículo que formaba parte de la edición de 1932 -y que, de hecho, se menciona en el "Prólogo" - no es ya parte del libro en 1957. La nota al pie comenta: "El artículo que ahora parecería muy débil, no figura en esta reedición" (1974: 177). Las razones por las que no figura se las puede encontrar sin mayor esfuerzo en el cambio de coyuntura.

El artículo al que se hace referencia es "Nuestras imposibilidades", que había aparecido en 1931 en la revista Sur y se había incluido en la primera edición de Discusión como primer texto del libro, pero en 1957 se lo considera "débil". El artículo es un análisis de importante valoración negativa ("quejas", se autodenomina en el propio texto) de los caracteres del argentino medio de las ciudades. No sería errado vincular la decisión de eliminar el artículo de la reedición de 1957 por sus conclusiones finales si se recuerda que el final del texto adjudicaba responsabilidades del "rencor" que define al argentino al "incomparable espectáculo de un gobierno conservador, que está forzando a toda la república a ingresar en el socialismo, sólo por fastidiar y entristecer a un partido medio". Si en su momento el fragmento hacía referencia al gobierno militar que había encabezado el golpe de Estado contra el presidente electo, Hipólito Yrigoyen; reeditado en 1957 el filo de los sentidos renovados podía interpelar al gobierno militar que había encabezado el golpe de Estado contra el presidente electo Juan Domingo Perón. Borges, que era entonces funcionario del gobierno instaurado por la autodenominada "Revolución Libertadora", sostenía para entonces que cualquier defensa del peronismo era un ataque a la "Revolución" y cualquier ataque a la "Revolución" una defensa encubierta del peronismo. (cf: "Una efusión de Ezequiel Martínez Estrada", publicado al año del golpe de estado en Sur, n²42, septiembre-octubre de 1956)

Pero volviendo a la edición de 1957 de Discusión y la inclusión de "El escritor argentino y la tradición", distinguíamos allí el borramiento de referencias cronológicas en el texto y la ambigüedad o ausencia de las indicaciones paratextuales. Una nueva operación se sostiene en esa modalidad sinuosa de las indicaciones y se incluye así al texto "El escritor argentino y la tradición" en el marco de un libro que se fecha a sí mismo en 1932, incorporando esa fecha, más no sea por omisión, como fecha de producción del artículo. 
Como decía el propio Borges: al agregar nuevos textos a un libro, estos lo "complementan o rectifican" (1974: 351). Y deberíamos agregar: el libro en el que se los incluye los modifica -los complementa, los rectifica- a ellos también. Al eliminarse los señalamientos que podrían advertir de lo contrario, el nuevo texto (la conferencia de 1951 en su edición corregida y reubicada editorial y cronológicamente), promueve otra operación de cambio del contexto de enunciación sobre el que interviene y, en simultáneo, borra su contexto de intervención previo, volviendo difuso así el fuerte carácter de intervención situada que había tenido anteriormente. Es una operación sutil y compleja la de 1957, pero al corregir las pequeñas referencias cronológicas de la conferencia de 1951, borronea el sentido de intervención contextual que tenía ese texto fuertemente antiperonista. En 1951, Borges era el presidente del opositor Sindicato Argentino de Escritores y dicta su conferencia en el ámbito sensiblemente antiperonista del Colegio Libre de Estudios Superiores: tanto en términos institucionales como en términos del contenido de la conferencia, ésta era una clara intervención política. Sin embargo, la reedición en libro de esa conferencia activamente borra el contexto histórico y cronológico de la intervención original y se camufla sin otra indicación de fechas bajo el amplio paraguas del "1932", año de la primera edición del libro Discusión.

Así como en 1951 se había transformado la que era originalmente -entre otras cosas, claro- una intervención estética antinazi convirtiéndola en un modo de la intervención antiperonista, en 1957 -caído el peronismo y con Borges reubicado como defensor a ultranza y funcionario de la autodenominada "Revolución Libertadora"-, la que ahora cambiará su sentido es la intervención antiperonista. Es en ese nuevo contexto que Borges corrige su conferencia, le desbarata las referencias cronológicas coherentes, la incluye en el libro de 1932 y decide no agregarle informaciones sobre su origen, informaciones que sí había considerado pertinente reponer al publicar en Otras inquisiciones su texto "Nathaniel Hawthorne", en 1952. En 1957, borra referencias y con ellas borronea el origen coyuntural de la intervención de 1951.

La sistemática política de reescritura que practica Borges sobre sus libros al ser reeditados cambia el sentido de esos libros, y los textos posteriores que se incluyen en libros anteriores cambian su sentido también. ${ }^{15}$ Cada libro de Borges debiera someterse a una lectura de inscripciones contextuales múltiples: la edición de 1932 de Discusión propone un modo de intervención que no será el mismo que cuando se la reedite en 1957. Correlativamente, la conferencia de 1951 no funciona del mismo modo al ser pronunciada que cuando es

\footnotetext{
${ }^{15}$ Sobre los efectos de lectura generados por las reescrituras que Borges imprime a los libros de los veinte hay mucho para decir. Como ejemplo, podemos leer la entrada del día 14 de mayo de 1955 del Borges de Bioy Casares. Escribe allí Bioy a propósito de la reedición de Evaristo Carriego en la colección de Obras completas (1955), para la cual Borges reescribe su ensayo de 1930 operando las mutaciones que venimos analizando para el caso de "El escritor argentino y la tradición": "Leo -anota Bioy-Evaristo Carriego, de Borges, en la edición de las Obras completas. Leo todo lo que no estaba en el libro original: 'Historias de jinetes', el prólogo: páginas que han convertido esa obra inmadura en un libro inteligente y agradable" (2006: 125; los dos últimos subrayados son nuestros). Para el análisis de un caso en particular, ver Hernaiz (2014).
} 
incluida en la edición de 1957 del libro que originalmente había sido publicado en 1932 y que arrastra esa fecha de origen como elemento central de su modo de circulación, aún pese a las diferencias existentes entre el libro de 1932 y el de 1957.

\section{Obras Citadas}

Avellaneda, Andrés. 1983. El habla de la ideología. Sudamericana: Buenos Aires.

Balderston, Daniel. 2013. "Detalles circunstanciales sobre dos borradores de `El escritor argentino y la tradición'”. La Biblioteca. Buenos Aires: Ediciones de la Biblioteca Nacional. 32-47.

Borges, Jorge Luis. 2011. Prólogos, con un prólogo de prólogos. Borges Oral. Buenos Aires: Sudamericana. . 1999. Borges en Sur (1931-1980). Buenos Aires: Emecé. . 1985. "Releyendo a Sarmiento". El País, Madrid: 12-02-85, disponible en http://elpais.com/diario/1985/12/02/opinion/502326008_850215.html . 1978. Prólogo a "La moneda de hierro". Obra poética. Buenos Aires: Emecé. . 1974. Obras Completas. Buenos Aires: Emecé. . 1957. Discusión. Buenos Aires: Emecé. . 1955. "El escritor argentino y la tradición". Sur 232, enero-febrero. . 1953. "El escritor argentino y la tradición". Cursos y conferencias XXI, XLII: 250-252.

. 1952. Otras inquisiciones. Buenos Aires: Sur. . 1951. "Nota sobre (hacia) Bernard Shaw". Sur 200, junio. . 1945. "Agradecimiento a la Sociedad Argentina de Escritores", Sur 129, julio. . 1944. Prólogo a "Domingo Faustino Sarmiento: Recuerdos de Provincia" Buenos Aires: Emecé Editores. . 1939. "Pierre Menard, autor del Quijote". Sur 56, mayo. . 1931. "Nuestras imposibilidades". Sur 4, noviembre.

Cousido, Diego y Sebastián Hernaiz. 2015. "Revista Poesía Argentina, una poética para la Nación". En Panella, Claudio y Korn, Guillermo, comps., Ideas y debates para la Nueva Argentina. Revistas culturales y politicas del peronismo (1946-1955). La Plata: UNLP-EPC.

Djament, Leonora. 2007. La vacilación afortunada. Buenos Aires: Editorial Colihue.

Genette, Gerard. 2001. Umbrales. Buenos Aires: Siglo XXI

Hernaiz, Sebastián. 2014. "Judería: De la denuncia al borroneo". Variaciones Borges 38 : $3-28$. . 2011. "Las tensiones de una revista", Revista N: 7.

Louis, Annick. 2007. Borges ante el fascismo. Bern: Peter Lang. . 1999. "Jorge Luis Borges: obras, completas y otras". Boletin 7: 41-62. . 1997. Jorge Luis Borges: Ouvre et manoeuvres. Paris: L'Harmattan. 
Marechal, Leopoldo. 1925. Revista Martín Fierro 26, II: 4.

Marechal, Leopoldo. 1950. "Lo autóctono y lo foráneo en su sentido esencial". Buenos Aires: Ministerio de Cultura y Educación. 181-192.

Murena, Héctor. 1948. "Condenación de una poesía". Sur 164.

Neiburg, Federico. 1988. Los intelectuales y la invención del peronismo. Buenos Aires: Alianza. Panesi, Jorge. 2007. "Borges y el peronismo". En Viñas, David, dir., y Guillermo Korn, comp., El peronismo clásico (1945-1955) Descamisados, gorilas y contreras. Literatura argentina Siglo XX. Buenos Aires: Paradiso - Fundación Crónica General.

Piglia, Ricardo. 2013. "Cuarto programa". En Televisión Pública Argentina (TVA). "Borges por Piglia”. Programa emitido el 28/09/2013. Disponible en el canal de YouTube de la TVA: https://www.youtube.com/watch?v=MUXFMRM7Jx0. Consulta: 20/03/2018.

Sarlo, Beatriz. 2003. Borges, un escritor en las orillas. Buenos Aires: Seix Barral.

S/F. 1949. Continente. Mensuario de arte, letras, ciencias, humor, curiosidades e interés general, número 26, 31/05/1949, Buenos Aires: 157.

Vázquez, Pablo A. 2010. "Continente. Tentativa cultural en el marco del primer peronismo". En Panella, Claudio y Guillermo Korn, comps., Ideas y debates para la nueva Argentina. Revistas culturales y politicas del peronismo (1946-1955). La Plata: Ediciones de Periodismo y Comunicación -UNLP. 
